\title{
Acute methemoglobinemia after a blast injury: a case report
}

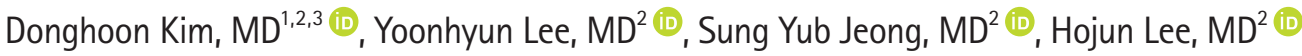 \\ 'Department of Critical Care Medicine, Armed Forces Capital Hospital, Seongnam, Korea \\ ${ }^{2}$ Armed Forces Trauma Center, Armed Forces Capital Hospital, Seongnam, Korea \\ ${ }^{3}$ Division of Cardiology, Department of Internal Medicine, Armed Forces Capital Hospital, Seongnam, Korea
}

Received: September 5, 2021

Revised: November 29, 2021

Accepted: December 1, 2021

Correspondence to

Hojun Lee, MD

Armed Forces Trauma Center, Armed

Forces Capital Hospital, 81 Saemaeul-

ro 177beon-gil, Bundang-gu,

Seongnam 13574, Korea

Tel: +82-31-789-2848

E-mail: dhltkd01@mnd.go.kr
Methemoglobin is a structurally modified form of hemoglobin incapable of binding oxygen, and elevated levels of methemoglobin cause tissue hypoxia. Occupational exposure to 2,4,6-trinitrotoluene, commonly called trinitrotoluene, causes methemoglobinemia. This case report describes a 27-year-old male sergeant who developed methemoglobinemia upon exposure to trinitrotoluene after a blast injury while welding the walls of tank shells. This is the first case of its kind in Korea. The patient had multiple burns in his abdomen and open fractures in his right leg. While his body temperature, heart rate, respiratory rate, arterial blood pressure, and chest X-ray were normal, arterial gas analysis revealed acute (methemoglobinemia concentration, 13.5\%; oxygen saturation, 92.0\%), probably caused by nitroglycerin exposure. Aspiration and adsorption through the skin and respiratory system were suspected to be the routes of entry. His methemoglobinemia normalized after 4 days after treating the wounds surgically, administering oxygen therapy, and performing blood transfusion.

Keywords: Methemoglobinemia; Trinitrotoluene; Blast injuries; Case reports

\section{INTRODUCTION}

Methemoglobin (MetHb) is a modified form of hemoglobin, in which $\mathrm{Fe}^{2+}$ (ferrous ion) is oxidized to $\mathrm{Fe}^{3+}$ (ferric ion). MetHb cannot bind oxygen; hence, it cannot carry oxygen. 2,4,6-trinitrotoluene (TNT) is a well-known explosive material. Methemoglobinemia induced by occupational exposure to TNT has been previously reported [1,2]. However, this is the first report describing the occurrence of methemoglobinemia in a man who was exposed to a blast injury while manipulating a TNT bomb in Korea.
This study was done in accordance with the Ethical Principles for Medical Research Involving Human Subjects outlined in the Helsinki Declaration in 1975 (revised 2013). The study was approved by the Institutional Review Board of the Armed Forces Capital Hospital (No. AFCH-21-IRB-006). The Institutional Review Board waived the requirement for written informed consent.

\section{CASE REPORT}

A previously healthy 27-year-old male sergeant was admitted be- 


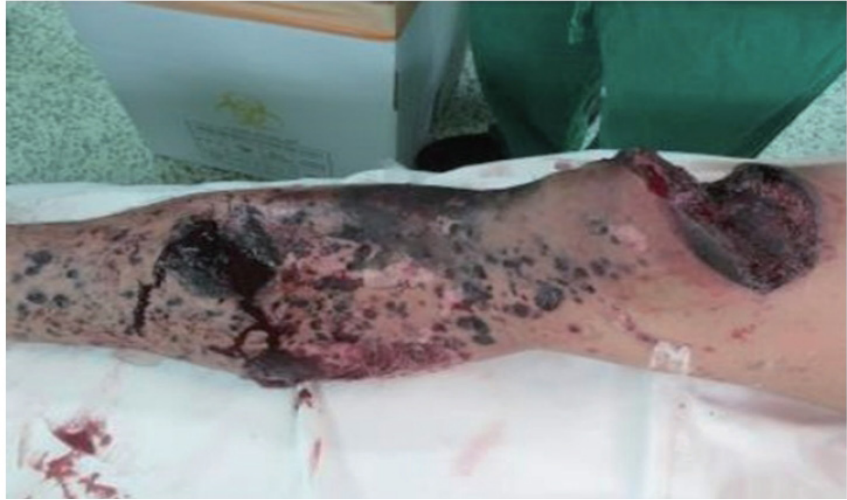

Fig. 1. Front surface of the right leg at admission. The patient provided written informed consent for the publication of the image.

Table 1. Arterial blood gas analysis (ABGA) on admission

\begin{tabular}{lcc}
\hline ABGA & Result & Reference \\
\hline $\mathrm{pH}$ & 7.35 & $7.35-7.45$ \\
$\mathrm{pCO}_{2}(\mathrm{mmHg})$ & 41.0 & $35-48$ \\
$\mathrm{pO}_{2}(\mathrm{mmHg})$ & 291.0 & $83-108$ \\
$\mathrm{HCO}_{3}(\mathrm{mmol} / \mathrm{L})$ & 22.6 & $21-28$ \\
$\mathrm{TCO}_{2}(\mathrm{mmol} / \mathrm{L})$ & 23.9 & $20-31$ \\
$\mathrm{O}_{2}$ saturation $(\%)$ & 99.4 & $94-100$ \\
Methemoglobin $(\%)$ & 13.5 & $\leq 1.5$ \\
\hline
\end{tabular}

cause of a blast injury during the welding of tank shells. He had multiple burns in his abdomen and open fractures in his right leg (Fig. 1). His body temperature was $36.3^{\circ} \mathrm{C}$, heart rate was $80 / \mathrm{min}$, respiratory rate was $20 / \mathrm{min}$, and arterial blood pressure was $159 / 90 \mathrm{mmHg}$. His chest X-ray was normal; however, nasal oxygen therapy was applied to deal with possible inhalation burns. His arterial blood was chocolate-colored, and the results of the arterial gas analysis are shown in Table 1. The analysis revealed acute methemoglobinemia. We could not use methylene blue for treatment since it was out of stock. Besides treating the wounds by surgery, we administered oxygen therapy and performed blood transfusion. His methemoglobinemia normalized after 4 days of hospital stay. A glucose-6-phosphate dehydrogenase (G-6-PDH) test was performed to identify the genetic cause of methemoglobinemia; the resulting (6.4 U/ $\mathrm{gHb}$ ) was within the normal range. The explosive component of the tank shells was TNT. Therefore, the patient was diagnosed with acute acquired methemoglobinemia caused by nitroglycerin exposure.

\section{DISCUSSION}

Acute methemoglobinemia may be caused by genetic factors
[3,4]. G-6-PDH deficiency and hemoglobin M disease are genetic factors that lead to methemoglobinemia, but their prevalence in the Korean population is very low [5-8]. However, the prevalence of these conditions in Korea is increasing with the increase in the number of Southeast Asian immigrants. Therefore, it should be considered in the differential diagnosis. Most cases of methemoglobinemia in Korea are due to exposure to various drugs or chemical compounds [9]. The patient in the present case did not have a family history or genetic cause other than his exposure to TNT after the blast injury. TNT is absorbed into the body via the digestive system, skin, or respiratory system [1]. In this case, it is suspected to have been absorbed via aspiration or through the skin. In the present case, the MetHb concentration was $13.5 \%$ and the ambient oxygen saturation as measured by pulse oximetry was $92.0 \%$.

When treating patients exposed to explosives in military or industrial settings, methemoglobinemia caused by exposure to nitroglycerin should be suspected. MetHb levels should be measured early through arterial blood gas analysis. Then, the necessary tests for tissue hypoxia should be performed. Patients with methemoglobinemia often show normal pulse oxygen saturation, even when experiencing severe tissue hypoxia; this may be misinterpreted as early hypoxia [10]. Since hypoxia can persist even with intensive oxygen therapy, early ventilator care may be required. If G-6-PDH deficiency is excluded and methemoglobinemia is severe and uncorrected, methylene blue may be used as the first-line treatment if available. However, in cases of trauma, where methylene blue is unavailable, red blood cell transfusion to correct bleeding may be used for treatment for methemoglobinemia. Active correction was required in this case, with repeated MetHb follow-up tests. Regarding this case, we believed that it was important for the Armed Forces Capital Hospital to report this case of poisoning due to an explosion, since this is the first such report in Korea.

\section{NOTES}

\section{Ethical statement}

The study was approved by the Institutional Review Board of the Armed Forces Capital Hospital (No. AFCH-21-IRB-006). The Institutional Review Board waived the requirement for written informed consent.

\section{Conflicts of interest}

The authors have no conflicts of interest to declare. 


\section{Funding}

None.

\section{Author contributions}

Conceptualization: all authors; Data curation: DK, HL; Formal analysis: all authors; Methodology: DK, HL; Project administration: all authors; Visualization: DK, HL; Writing-original draft: DK, HL; Writing-review \& editing: all authors.

All authors read and approved the final manuscript.

\section{REFERENCES}

1. Hathaway JA. Subclinical effects of trinitrotoluene: a review of epidemiology studies. In: Rickert DE, editor. Toxicity of nitroaromatic compounds. Washington: Hemisphere Publishing Corporation; 1985. p. 255-74.

2. Zimmerman H. Chemical hepatic injury. In: Haddad LM, Shannon MW, Winchester JF, editors. Clinical management of poisoning and drug overdose. Philadelphia: Saunders; 1998. p. 149-74.

3. Nagel R. Disorders of hemoglobin function and stability. In: Handin RI, Lux SE, Stossel TP, editors. Blood principles and practice of hematology. Philadelphia: Lippincott; 1995. p. 1591-644.
4. Baraka AS, Ayoub CM, Kaddoum RN, Maalouli JM, Chehab IR, Hadi UM. Severe oxyhemoglobin desaturation during induction of anesthesia in a patient with congenital methemoglobinemia. Anesthesiology 2001;95:1296-7.

5. Saha N. Distribution of glucose-6-phosphate dehydrogenase phenotypes in five East Asian population groups. Ann Acad Med Singap 1984;13:494-7.

6. Blackwell RQ, Ro IH, Yen L. Low incidence of erythrocyte G-6- PD deficiency in Koreans. Vox Sang 1968;14:299-303.

7. Goo YK, Ji SY, Shin HI, et al. First evaluation of glucose6-phosphate dehydrogenase (G6PD) deficiency in vivax malaria endemic regions in the Republic of Korea. PLoS One 2014;9:e97390.

8. Kim DS, Baek HJ, Kim BR, Yoon BA, Lee JH, Kook H. The first Korean family with hemoglobin-M Milwaukee-2 leading to hereditary methemoglobinemia. Yonsei Med J 2020;61: 1064-7.

9. Hall AH, Kulig KW, Rumack BH. Drug- and chemical-induced methaemoglobinaemia. Clinical features and management. Med Toxicol 1986;1:253-60.

10. Anderson ST, Hajduczek J, Barker SJ. Benzocaine-induced methemoglobinemia in an adult: accuracy of pulse oximetry with methemoglobinemia. Anesth Analg 1988;67:1099-101. 